\title{
Polymorphism T81C in H-RAS Oncogene Is Associated With Disease Progression in Imatinib (TKI) Treated Chronic Myeloid Leukemia Patients
}

\author{
Rashid Mir ${ }^{\mathrm{a}, \mathrm{d}}$, Imtiyaz Ah ${ }^{\mathrm{b}, \mathrm{d}}$, Jamsheed Javid ${ }^{\mathrm{b}}$, Mariyam Zuberi ${ }^{\mathrm{b}}$, Sameer Guru ${ }^{\mathrm{b}}$, Masroor Mirza ${ }^{\mathrm{b}}$, \\ Shazia Farooq ${ }^{b}$, Prasant Yadav ${ }^{b}$, Prakash C. Ray ${ }^{b}$, Naresh Guptac ${ }^{c}$, Alpana Saxena ${ }^{b}$ e
}

\begin{abstract}
Background: Mammalian cells contain three functional RAS protooncogenes, known as H-RAS, K-RAS, and N-RAS, which encode small GTP-binding proteins in terms of $\mathrm{p} 21^{\mathrm{ras}} \mathrm{s}$. RAS genes have been elucidated as major participants in the development and progression of cancer. A single nucleotide polymorphism (SNP) at H-RAS cDNA position $81 \mathrm{~T} \rightarrow \mathrm{C}$ (rs12628) has been found to be associated with the risk of many human cancers like gastrointestinal, oral, colon, bladder and thyroid carcinomas. Therefore, we hypothesized that this polymorphisms in H-RAS could influence susceptibility to chronic myeloid leukemia as well, and we conducted this study to test the hypothesis in Indian population.
\end{abstract}

Method: H-RAS polymorphism was studied in 100 chronic myeloid leukemia (CML) patients and 100 healthy controls by restriction fragmentation length polymorphism (RFLP-PCR). Associations between polymorphism and clinicopathological features of CML patients were investigated.

Results: In CML patients, the TT, TC and CC genotype frequency was $38 \%, 61 \%$ and $1 \%$ respectively, compared to $92 \%, 8 \%$ and $0 \%$ in healthy controls respectively. Compared to TT genotype, CT was significantly associated with increased risk of CML (odds ratio (OR): $8.4, \mathrm{P}<0.00001)$. There was a statistically significant correlation of H-RAS polymorphism with phases $(\mathrm{P}<0.0003)$, molecular response $(\mathrm{P}<0.0001)$, hematological response $(\mathrm{P}<0.04)$ and thrombocytopenia $(\mathrm{P}<0.003)$. However, there was no correlation of this polymorphism found with other clinical parameters.

Conclusion: H-RAS T81C polymorphism was found to be associated

Manuscript accepted for publication April 14, 2015

aFaculty of Applied Medical Sciences, University of Tabuk, Tabuk 71491, Saudi Arabia

${ }^{b}$ Cancer Genetics Lab, Department of Biochemistry and Associated Hospitals, New Delhi, India

'Department of Medicine, Maulana Azad Medical College and Associated Hospitals, New Delhi, India

${ }^{\mathrm{d}}$ These authors contributed equally to this paper.

${ }^{e}$ Corresponding Author: Alpana Saxena, Department of Biochemistry and Associated Hospitals, New Delhi, India. Email: drrashidmamc@gmail.com

doi: http://dx.doi.org/10.14740/wjon912e with CML risk and prognosis of CML. These results suggest that $\mathrm{C}$ heterozygosis may be considered a potential risk factor for CML development in the North Indian population.

Keywords: H-RAS T81C polymorphism; Restriction fragmentation length polymorphism; H-RAS; K-RAS; N-RAS; Chronic myeloid leukemia

\section{Introduction}

Chronic myeloid leukemia (CML) is a clonal myeloid stem cell disorder characterized by excessive accumulation of clonal myeloid cells in hematopoietic tissues. Clinically CML can be divided into three phases: the chronic phase $(\mathrm{CP})$, the accelerated phase (AP), and the blast crisis (BC) $[1,2]$. It occurs with an annual incidence of $1.0-1.5$ per 100,000 persons [3]. CML occurs very rarely in children. More than $90 \%$ of CML patients are diagnosed when their disease is in a relatively early phase known as the CP [3]. CML is characterized by the presence of the Philadelphia $(\mathrm{Ph})$ chromosome, a shortened 22 chromosome resulting from a $(9 ; 22)(\mathrm{q} 34 ; \mathrm{q} 11)$ reciprocal translocation that juxtaposes the c-abl oncogene 1 (ABL1) gene on chromosome 9 with the breakpoint cluster region (BCR) gene on chromosome 22 [4]. This reciprocal translocation gives rise to BCR-ABL fusion oncogene, resulting in fusion messenger RNA molecules (e1a2, b2a2, b3a2, and e19a2) of different lengths that are translated into different chimeric protein products (p190, p210 and p230 BCR$\mathrm{ABL}$ respectively) that are characterized by constitutive activation of its tyrosine kinase activity [5]. H-RAS, K-RAS, and N-RAS are the three functional RAS proto-oncogenes, which encode small GTP-binding proteins. RAS genes have been characterized as major participants in the development and progression of a series of human tumors, such as gastrointestinal cancer, lung cancer, thyroid cancer, melanoma, and breast cancer [6]. H-RAS, N-RAS, and K-RAS proteins are widely expressed, with K-RAS expressing in almost all cell types. Members of the RAS gene family code for proteins of molecular weight 21,000 (p21); these proteins are membrane bound. They bind with GTP during their active state and GDP during their inactive state. The switch between their inactive and active forms, together with their ability to bind to target 
Table 1. Hematologic Responses

\begin{tabular}{lll}
\hline Complete or major hematological response & Partial or minor hematological response & Lose or minimal hematological response \\
\hline Platelet count $>150 \times 10^{9} / \mathrm{L}$ & Platelet count $<450 \times 10^{9} / \mathrm{L}$ & Platelet count $<450 \times 10^{9} / \mathrm{L}$ \\
WBC count $<10 \times 10^{9} / \mathrm{L}$ & WBC count $>10 \times 10^{9} / \mathrm{L}$ & WBC count $>20 \times 10^{9} / \mathrm{L}$ \\
Basophils: $<5 \%$ & Basophils: $>10 \%$ & Basophils: $15 \%$ \\
Differential without immature granulocytes & Presence of blasts and promyelocytes in & Presence of blasts and promyelocytes in \\
Absence of blasts and promyelocytes in & peripheral blood & peripheral blood \\
peripheral blood & Spleen: palpable spleen & Spleen: palpable spleen \\
Spleen: non-palpable spleen & & \\
\hline
\end{tabular}

proteins, provides the mechanism for the cell differentiation, development and proliferation [7, 8]. Harvey-RAS (H-RAS) gene is located on chromosome 11 [9]. Oncogenic point mutations, namely the hotspot mutations in codons 12,13 and 61 , are frequently observed in many tumor types [10]. Besides the mutation hotspots, inherited polymorphisms in the H-RAS sequence were described $[11,12]$. A single nucleotide polymorphism (SNP) at H-RAS cDNA position 81T/C (rs12628), in codon 27 of exon 1, was shown to be associated with the risk of human cancers [13]. H-RAS T/C polymorphism does not impair p21 protien structure and function as both CAT and CAC codons encode histidine (His27His). However, it was recently demonstrated that the $\mathrm{C}$ allele of this SNP could increase the risk of urinary bladder cancer, colon, and gastric cancer [14-16].

Therefore, in the present research, we hypothesize that the H-RAS T81C polymorphism may have an effect on the $\mathrm{H}$ RAS activity, and ultimately may play a role in modulating the susceptibility to leukemia. In order to verify our hypothesis, a population-based case-control study was conducted to investigate the association between the H-RAS T81C genotypes and the risk of CML in Indian population.

\section{Material and Methods}

\section{Sample collection}

Peripheral blood samples, i.e. $5 \mathrm{~mL}$ venous blood samples, were collected in EDTA vials from $100 \mathrm{CML}$ patients as well as from 100 healthy donors. Buffy coat was isolated and washed in red cells lysis buffer. All samples were stored at -80 ${ }^{\circ} \mathrm{C}$ until the RNA and genomic DNA was extracted. The diagnosis was confirmed by detecting $\mathrm{t}(9 ; 22)$ or BCR/ABL fusion gene $\left(\mathrm{p} 210^{\mathrm{bcr}-\mathrm{abl}}\right)$ which is further categorized into $\mathrm{b} 3 \mathrm{a} 2$ or b2a 2 subtypes on the basis of the BCR breakpoint by reverse transcription polymerase chain reaction in the Molecular On- cology Lab, Department of Biochemistry.

\section{Selection criteria of patients}

\section{Inclusion criteria}

The study included newly diagnosed CML patients treated with imatinib mesylate with a dose of 400 to $800 \mathrm{mg} /$ day. All three stages of cases were included: CP, AP, and BC.

\section{Exclusion criteria}

The exclusion criteria included chronic myelomonocytic leukemia (CMML) patients, and other myeloproliferative disorder patients. The patients' follow-up was maintained regularly and samples were collected after every 6 months for imatinib response and mutation studies. The classic criteria used for imatinib mesylate responses in CML for hematologic and molecular responses are depicted in Tables 1 and 2.

\section{RNA isolation}

Total RNA was isolated from mononuclear cells with guanidinium isothiocyanate (Trizol LS ${ }^{\mathrm{TM}}$, Invitrogen), according to the protocol provided by the manufacturer. The presence of RNA was confirmed by running the product on $2 \%$ agarose gel.

\section{cDNA synthesis}

The concentration of RNA was measured spectrophotometrically. cDNA was then synthesized using M-MuLV reverse transcriptase and other reaction components (Fermentas Cat.

Table 2. Molecular Response

Major molecular response
It indicates non-quantifiable and non-detectable BCR-ABL gene
transcript (BCR-ABL/ABL) $\leq 0.10^{3 *}$
check every 3 months

*BCR-ABL to control gene ratio according to international scale (IS).

\section{Minimal or no molecular response}

It indicates quantifiable and detectable BCR-ABL gene transcript (BCR-ABL/ABL) $\geq 0.10^{3 *}$

check every 3 months 
Table 3. Sequence of Oligonucleotides Used in Multiplex RTPCR for Detection of BCR-ABL Transcript as the Target Gene and BCR Transcripts as the Internal Control

\section{BCR-ABL primers \\ C5e 5'-ATAGGATCCTTTGCAACCGGGTCTGAA-3' \\ B2B 5'-ACAGAATTCCGCTGACCATCAATAAG-3' \\ BCR-C 5'-ACCGCATGTTCCGGGACAAAAG-3' \\ CA3 5'-TGTTGACTGGCGTGATGTAGTTGCTTGG-3'}

No. K1622), according to the protocol provided by the manufacturer.

\section{Multiplex RT-PCR for BCR-ABL}

BCR-ABL transcripts were detected using allele-specific primers for p210 and p190 primer sequences, as already described [17] listed in Table 3. PCR was carried out in a total volume of $25 \mu \mathrm{L}$ reaction mixture containing $1 \mathrm{U} / \mu \mathrm{L}$ Taq polymerase, $240 \mu \mathrm{M} \mathrm{dNTP,}, 1.8 \mathrm{M} \mathrm{MgCl}_{2}$, and $0.6 \mu \mathrm{M}$ of primers. A program was employed, under the following conditions: an initial denaturation step at $95^{\circ} \mathrm{C}$ for $10 \mathrm{~min}$, then followed by $40 \mathrm{cy}$ cles of denaturing at $94{ }^{\circ} \mathrm{C}$ for $40 \mathrm{~s}$, primer annealing at $55^{\circ} \mathrm{C}$, extension at $72{ }^{\circ} \mathrm{C}$ for $45 \mathrm{~s}$, and a final extension step at $72{ }^{\circ} \mathrm{C}$ for $5 \mathrm{~min}$. The expected bands were as follows: $808 \mathrm{bp}$, normal BCR; 481 bp, e1a2; 385 bp, b3a2; 310 bp, b2a2.

\section{DNA extraction}

Genomic DNA from peripheral blood was extracted using genomic DNA extraction kit (Gene Aid Cat. No. GB 100). The quality and integrity of the DNA was determined by the A260/280 ratios.

\section{H-RAS T81C genotyping}

H-RAS T81C polymorphism located in exon 1 was analyzed by RFLP-PCR using DRAIII enzyme. Restriction fragmentation length polymorphism (RFLP) assay was performed at cancer genetics laboratory, MAMC, New Delhi. A 200-bp segment was amplified by RFLP primers reported from elsewhere [14] represented in Table 4.

The amplification was accomplished with a $25 \mu \mathrm{L}$ reaction mixture containing $5 \mu \mathrm{L}$ of $20 \mathrm{ng}$ template DNA, 0.25 $\mu \mathrm{L}$ of 25 pmol each primer, $2.5 \mu \mathrm{L} 10 \mathrm{mM}$ dNTPs, $1.5 \mu \mathrm{L}$ of $20 \mathrm{mM} \mathrm{MgCl}_{2}, 0.3 \mu \mathrm{L}$ of $5 \mathrm{U} / \mu \mathrm{L}$ Taq polymerase with 2.5

Table 4. Sequence of Oligonucleotides Used in Allele Specific PCR of H-RAS Gene

\begin{tabular}{ll}
\hline Gene & H-RAS \\
\hline Forward primer & 5'-CTTGGCAGGTGGGGCAGGAGA-3' \\
Reverse primer & 5'-GGCACCTGGACGGCGGCGCTAG-3' \\
\hline
\end{tabular}

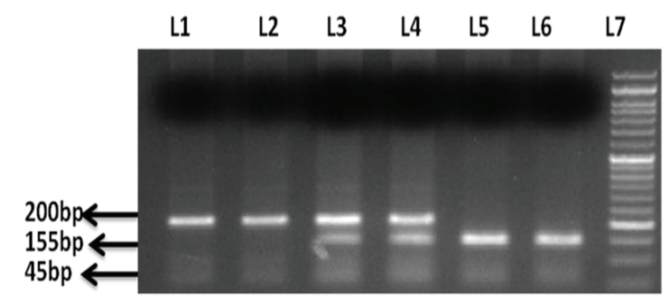

L1,L2 = Patient 1and 2 homozygous for TT genotype with $200 \mathrm{bp}$ size. $\mathrm{L} 3, \mathrm{~L} 4=$ Patient 3 and 4 heterozygous for CT genotype with $200 \mathrm{bp}, 145 \mathrm{bp}$ and $55 \mathrm{bp}{ }^{*}$ ) size fragments.

$\mathrm{L} 5, \mathrm{~L} 6=$ Patient 5 and 6 homozygous for CC genotype with $145 \mathrm{bp}$ and $55 \mathrm{bp}{ }^{*}$ size.

* 55bp not visible in primer dimer.

Figure 1. Ethidium bromide stained agarose gel electrophoresis image of H-RAS T81C polymorphism.

$\mu \mathrm{L}$ of $10 \times$ Taq buffer (FD1224, Fermantas). The amplification conditions were $10 \mathrm{~min}$ of initial denaturation at $95^{\circ} \mathrm{C}, 40$ cycles at $95{ }^{\circ} \mathrm{C}$ for $45 \mathrm{~s}$, annealing temperature at $60{ }^{\circ} \mathrm{C}$ for 45 $\mathrm{s}$ and $72{ }^{\circ} \mathrm{C}$ for $45 \mathrm{~s}$ with a final $10 \mathrm{~min}$ extension step at 72 ${ }^{\circ} \mathrm{C}$. Amplified PCR product $(15 \mu \mathrm{L})$ was digested with $1 \mu \mathrm{L}$ of $10 \times$ digestion buffer containing 3 units fast digestion DraIII ((FD1224, Fermantas). After $15 \mathrm{~min}$ digestion at $37^{\circ} \mathrm{C}$, the fragments were separated on a $2 \%$ agarose gel stained with ethidium bromide. TT homozygote presented a single fragment of $200 \mathrm{bp}$, the CC homozygote with DraIII restriction site was cut into fragments of $145 \mathrm{bp}$ and $55 \mathrm{bp}$, whereas the heterozygous CT genotype presented all the three fragments as shown in Figure 1.

Table 5. Clinical-Pathological Parameters of CML Patients

\begin{tabular}{lll}
\hline & No. & $\%$ \\
\hline Patients & 100 & $100 \%$ \\
controls & 100 & $100 \%$ \\
Males & 65 & $65 \%$ \\
Female & 35 & $35 \%$ \\
CP-CML & 50 & $50 \%$ \\
AP-CML & 25 & $25 \%$ \\
BC-CML & 25 & $25 \%$ \\
Imatinib & 100 & $100 \%$ \\
MMR & 52 & $52 \%$ \\
No MR & 48 & $48 \%$ \\
MHR & 50 & $50 \%$ \\
Minor HR & 10 & $10 \%$ \\
Loss HR & 40 & $40 \%$ \\
Age $>45$ & 36 & $36 \%$ \\
Age $<45$ & 64 & $64 \%$ \\
Thrombocytopenia & 50 & $50 \%$ \\
No thrombocytopenia & $50 \%$ \\
\hline & & \\
\hline M & 50 & \\
\hline
\end{tabular}


Table 6. Association of H-RAS T81C Polymorphism With the Clinicopathological Features

\begin{tabular}{llllll}
\hline Clinical features & No. & TT & CT & CC & P value \\
\hline Patients & 100 & 38 & 61 & 1 & $<0.0001$ \\
Controls & 100 & 92 & 8 & 0 & \\
Males & 65 & 25 & 39 & 1 & $<0.7$ \\
Female & 35 & 13 & 22 & 0 & \\
CP-CML & 50 & 29 & 20 & 1 & $<0.0003$ \\
AP-CML & 25 & 7 & 18 & 0 & \\
BC-CML & 25 & 2 & 23 & 0 & \\
A2b2 & 31 & 13 & 18 & 0 & $<0.9$ \\
A2b3 & 67 & 24 & 42 & 1 & \\
A2b2/A2b3 & 2 & 1 & 1 & 0 & \\
Imatinib & 100 & 38 & 61 & 1 & \\
MMR & 52 & 31 & 21 & 0 & $<0.0001$ \\
No MR & 48 & 7 & 40 & 1 & \\
MHR & 50 & 26 & 24 & 0 & $<0.04$ \\
Minor HR & 10 & 3 & 7 & 0 & \\
Loss HR & 40 & 9 & 30 & 1 & $<0.2$ \\
Age $>45$ & 36 & 11 & 24 & 1 & \\
Age $\leq 45$ & 64 & 27 & 37 & 0 & \\
Thrombocytopenia & 50 & 11 & 38 & 1 & \\
No thrombocytopenia & 50 & 27 & 23 & 0 & \\
\hline
\end{tabular}

\section{Statistical analysis}

CML patients and controls were compared by statistical analysis performed using the SPSS 16.0 software package. Chi-square analysis and Fisher exact test were carried out to compare H-RAS T81C frequency with several clinical aspects, including sex, age, stage, BCR-ABL type, and thrombocytopenia. Hardy-Weinberg equilibrium was tested by a $\chi^{2}$ test to compare the observed genotype frequencies within the casecontrol groups. The associations between H-RAS T81C variant genotypes and risk of CML were estimated by computing the odds ratios (ORs) and their $95 \%$ confidence intervals (CIs) from both univariate and multivariate logistic regression analysis. $P$ value of $\leq 0.05$ was considered statistically significant.

\section{Results}

The study includes $100 \mathrm{CML}$ patients and 100 healthy controls frequency matched with age and gender. A total of 65 males and 35 females already diagnosed with CML were included in the study. Two age groups were made, patients aged $>45$ years included 36 cases, and above $<45$ included 64 cases. The demographic characteristics of the study subjects, age and gender of patients, BCR-ABL type, thrombocytopenia, molecular response and hematological response are summarized in Table 5. Patients with a history of previous cancer were excluded. The Institutional Ethics Committees of Maulana Azad Medical
College, New Delhi, India, approved the study and all patients provided written informed consent.

\section{H-RAS T81C genotyping frequency}

We identified frequent $\mathrm{T}>\mathrm{C}$ variation in codon 27 of exon 1 at cDNA position 81 of H-RAS, and the frequency of H-RAS genotypes for TT, CT and CC was $38 \%, 61 \%$ and $1 \%$ in patients compared to $92 \%, 8 \%$ and $0 \%$ in healthy controls. A statistically significant difference was observed between patients and healthy controls $(\mathrm{P}>0.0001)$. Genotyping results are summarized in Table 6 . The frequencies of $\mathrm{T}$ allele and

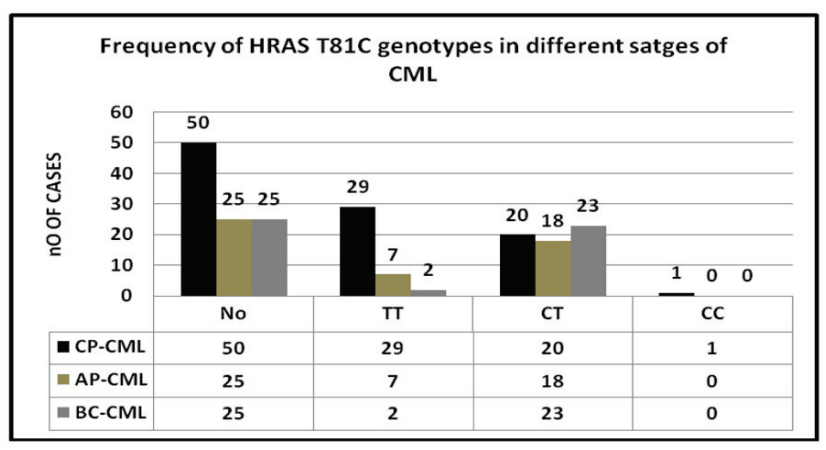

Figure 2. Association of H-RAS T81C with stages of CML. 
Table 7. Risk of CML Associated With the H-RAS Genotypes

\begin{tabular}{lllll}
\hline Genotyping & Cases $(\mathbf{n}=\mathbf{1 0 0})$ & Control $(\mathbf{1 0 0})$ & OR* $(\mathbf{9 5 \%} \mathbf{C I})$ & P value \\
\hline TT & $38(38 \%)$ & $92(92 \%)$ & 1 & \\
TC & $61(61 \%)$ & $8(8 \%)$ & $18.4(8.0-14.2)$ & $<0.0001$ \\
CC & $1(61 \%)$ & $0(0 \%)$ & - & \\
Allele type & & & & \\
$\quad$ T allele & $136(68.6 \%)$ & $184(95.8 \%)$ & 1 & $<0.0001$ \\
$\quad$ C allele & $62(32.2 \%)$ & $8(4.1 \%)$ & $10.4(4.8-22.6)$ & \\
\hline
\end{tabular}

OR: odds ratio.

$\mathrm{C}$ allele were 0.69 and 0.32 and allele frequencies were consistent with Hardy-Weinberg equilibrium. The frequency of $\mathrm{C}$ rare allele observed in CML was about $32.2 \%$ which was significantly higher than that in controls $4.1 \%\left(\chi^{2}=48.7, \mathrm{P}<\right.$ $0.00000001)$. However, there was a non-significant correlation found between H-RAS T81C polymorphism and the clinical features like age, gender, imatinib therapy and BCR-ABL transcripts.

\section{H-RAS genotype frequency in CML phases}

A statistically significant correlation was found between $\mathrm{H}$ RAS genotypes in CML phases. The rare $\mathrm{C}$ allele considerably increased from chronic phase to advanced phase patients. The genotype frequencies for TT, CT and CC were 58\%, 40\% and $2 \%$ in CP, $28 \%, 72 \%$ and $0 \%$ in AP and $8 \%, 92 \%$ and $0 \%$ in BC respectively (Fig. 2). The CT heterozygosity was a common feature of $\mathrm{AP}$ and $\mathrm{BC}$ phase CML compared to TT homozygote suggesting that H-RAS T81C polymorphism plays a significant role in the progression of CML.

\section{Correlation of H-RAS polymorphism with molecular re- sponse}

Among the $100 \mathrm{CML}$ patients at the time of analysis, 52 displayed major MR, 48 minimal or no molecular responses. In MMR (major) group, 52.6\%, $47.4 \%$ and $0 \%$ patients displayed TT, CT and CC genotypes compared to $17.5 \%, 83.3 \%$ and $0.2 \%$ genotypes in $\mathrm{m}$ HR (minor) respectively. A statistically significant difference was found between the two groups $(\mathrm{P}<$ 0.0001).

\section{Correlation of H-RAS T81C polymorphism with hemato- logical response}

Fifty CML patients had major HR, 10 minor HR and 40 minimal hematological responses respectively. The frequencies of H-RAS T81C genotypes TT, CT and CC were 52\%, 48\% and $0 \%$ in MHR, 30\%, 70\% and $0 \%$ in minor HR and $22.5 \%, 75 \%$ and $2.5 \%$ in loss HR group respectively. A significant correlation $(\mathrm{P}<0.04)$ was reported between H-RAS polymorphism and hematological response in CML patients.

\section{Correlation of H-RAS T81C polymorphism with thrombo- cytopenia}

Higher percentage of heterozygosity was detected in patients with thrombocytopenia. The genotype frequencies were $22 \%$, $76 \%$ and $2 \%$ in thromocytopenia group and $54 \%, 46 \%$ and $0 \%$ in no thrombocytopenia group for TT, CT and CC genotypes respectively. A statistically significant correlation was detected $(\mathrm{P}=0.003)$.

\section{H-RAS T81C polymorphism and CML risk}

An unconditional logistic regression was used to estimate associations between the genotypes and risk of CML (Table 7). It was found that an increased risk of CML was associated with the $\mathrm{C}$ allele. Compared to the TT genotype, the OR of 18.4 (8.0 - 14.2) for the CT genotype, it was found that there was about more than 18-fold risk associated with heterozygosity, suggesting a possible dominant effect of this polymorphism in CML Indian population. Thus, carrying out OR calculation, it became possible to assess whether the occurrence of the polymorphic variants of H-RAS gene at codon 27 was in any way associated with the increased susceptibility to CML.

\section{Discussion}

RAS small GTPases are activated in many hematopoietic growth factor signaling and in hematological malignancies, but their role in hematopoiesis and leukemogenesis is not completely known. In addition to their normal cellular functions, RAS proteins play critical roles in tumorigenesis. Several molecular alterations in the RAS genes have been identified such as minisatellites and acquired mutations in various cancers. Mutated RAS genes are associated with approximately $30 \%$ of all human cancers, including both solid tumors and hematological malignancies [10].

In addition to the direct activation by mutations, RAS can also be functionally activated by other oncogenic mutations, such as the BCR/ABL fusion protein. Likewise, increased levels of RAS activation have been linked to CML resulting from the $\mathrm{Brc} / \mathrm{Abl}$ translocation creating the Philadelphia chromosome [10]. Mutations in the RAS family of proto-oncogenes (H-RAS, N-RAS, and K-RAS) appear frequently in acute leukemias [18, 
Table 8. Frequency of T81C Genotypes in Different Cancers

\begin{tabular}{lllll}
\hline Cancer type & TT genotype & CT genotype & CC genotype & References \\
\hline Rectal cancer & $75.2 \%$ & $24.7 \%$ & $0 \%$ & 16 \\
Colon cancer & $76.3 \%$ & $21.5 \%$ & $2.1 \%$ & 16 \\
Gastric cancer & $79.24 \%$ & $19.87 \%$ & $0.89 \%$ & 16 \\
Thyroid cancer & $37.6 \%$ & $44.7 \%$ & $17.7 \%$ & 29 \\
Urinary bladder cancer & $48.3 \%$ & $38.1 \%$ & $13.4 \%$ & 34 \\
Colon cancer & $60.5 \%$ & $36.5 \%$ & $3 \%$ & 35 \\
Oral cancer & $53.7 \%$ & $39.4 \%$ & $6 \%$ & 36 \\
Urinary bladder cancer & $34.1 \%$ & $48.5 \%$ & $17.4 \%$ & 37 \\
\hline
\end{tabular}

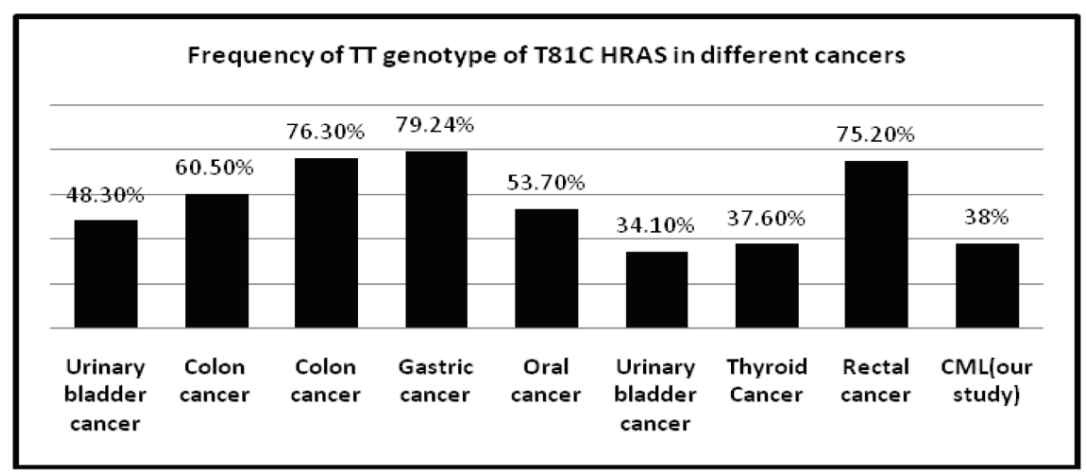

Figure 3. Frequency of TT genotype of T81C H-RAS in different cancers.

19]. Moreover, mutations in RAS genes may on occasion contribute to the transition from chronic-phase CML to the BC [20].

The role of H-RAS gene polymorphism in the pathogenesis of CML has not been reported. It has been suggested that H-RAS gene acts as enhancers of gene transcription. It was reported that polymorphic loci SNP $81 \mathrm{~T}>\mathrm{C}$ can indicate an increased risk of different types of human tumors, bladder, oral, gastrointestinal cancers, breast, lung, and skin [14, 16, 21-24]. H-RAS 81T-C polymorphism may induce aneuploidy through overexpression of the active p21 isoform of H-RAS in follicu- lar thyroid tumors [25]. SNP 81T3C, although it does not alter the amino acid sequence of the p21 RAS protein, may affect the expression of the gene inducing overexpression [26]. It is conceivable that SNP $81 \mathrm{~T}>\mathrm{C}$ is linked to other polymorphic sites in functional intron regions of H-RAS.

We identified frequent polymorphism in the coding region of $\mathrm{H}-\mathrm{RAS}$ in cDNA position $81 \mathrm{~T}>\mathrm{C}$, which appeared to be a marker for the risk of CML development and progression. Our results show that heterozygote carriers of the variant $\mathrm{C}$ allele at the site of $\mathrm{C} / \mathrm{T}$ polymorphism at codon 27 of the H-RAS gene

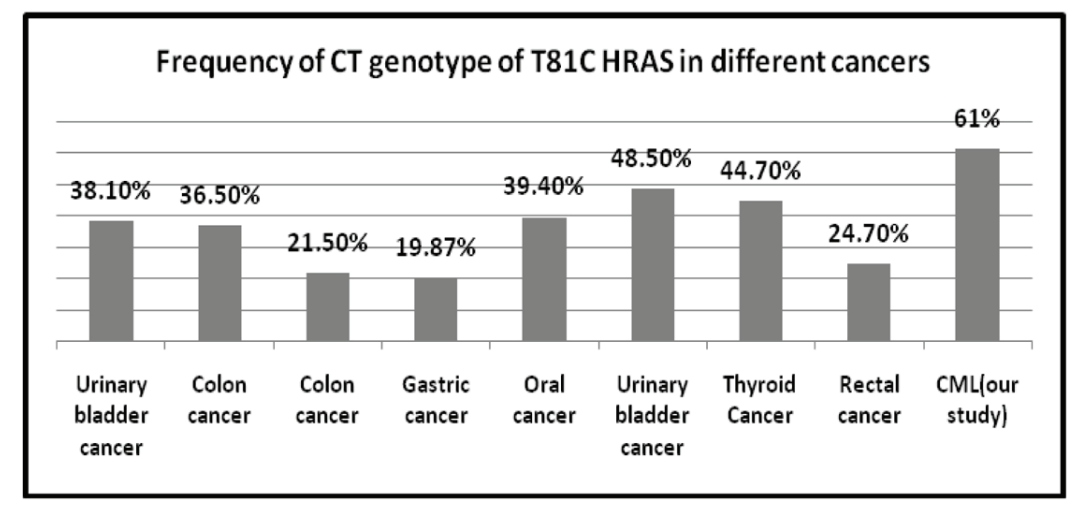

Figure 4. Frequency of CT genotype of T81C H-RAS in different cancers. 
have a decreased risk of CML. To confirm this, we screened cases and controls for T81C polymorphism. An unconditional logistic regression was performed to find the association of $\mathrm{H}$ RAS polymorphism with CML; we found an 18-fold increased risk of CML in carriers of the heterozygous $\mathrm{CT}$ genotype in comparison to wild-type carriers (TT) (P>0.0001, OR: 18.4). $\mathrm{H}-\mathrm{RAS} 81 \mathrm{C}$ allele has been shown to be a dominant genetic susceptibility factor for the development of many cancers in comparison to T allele; individuals harboring the homozygous and heterozygous $81 \mathrm{C}$-genotype are at an increased risk of thyroid cancer, gastric cancer, colon cancer, bladder and oral cancer [14-16, 27-29].

The frequency of T81C genotypes in different solid tumors is represented in Table 8 [14-16, 25, 29, 30] and also frequency of TT and CT genotype of T81C H-RAS in different cancers is shown Figures 3 and 4. Several molecular alternations in RAS gene have been identified such as minisatellites and mutations; however, research on the SNP in RAS gene was rare. This observation indicates that the distribution of H-RAS T81C polymorphism seems to be genetically different in various ethnics.

We found a strong association of H-RAS T81C polymorphism with the poor progression of CML. Compared to TT genotype, CT-genotype occurred more frequently in patients showing no molecular response and loss of hematogical response than good responders $(\mathrm{P}<0.0001$ and $\mathrm{P}<0.003)$. Moreover, we found a statistically significant correlation of this polymorphism with thrombocytopenia with a higher of rare $\mathrm{C}$ allele in thrombocytoprenic group patients. We found a significant association of $\mathrm{C}$ allele occurrence in CML patients to the transition from $\mathrm{CP} C \mathrm{CML}$ to the $\mathrm{BC}(\mathrm{P}<0.0003)$.

\section{Conclusion}

In conclusion, a frequent genetic polymorphism in the H-RAS proto-oncogene appears to be epidemiologically relevant for CML risk and progression. Its possible polymorphic loci in $\mathrm{H}-$ RAS could be a promising subject of additional studies.

\section{Acknowledgement}

The authors are grateful to all the patients who formed the study group.

\section{Competing Interests}

The authors declare that they have no competing interests.

\section{References}

1. Savage DG, Szydlo RM, Goldman JM. Clinical features at diagnosis in 430 patients with chronic myeloid leukaemia seen at a referral centre over a 16-year period. Br J Haematol. 1997;96(1):111-116.

2. Spiers AS. The clinical features of chronic granulocytic leukaemia. Clin Haematol. 1977;6(1):77-95.

3. Perrotti D, Jamieson C, Goldman J, Skorski T. Chronic myeloid leukemia: mechanisms of blastic transformation. J Clin Invest. 2010;120(7):2254-2264.

4. Chasseriau J, Rivet J, Bilan F, Chomel JC, Guilhot F, Bourmeyster N, Kitzis A. Characterization of the different BCR-ABL transcripts with a single multiplex RTPCR. J Mol Diagn. 2004;6(4):343-347.

5. Nowell PC, Hungerford DA. A minute chromosome in human chronic granulocytic leukemia. Science. 1960;132:1497-1499.

6. Barbacid M. ras genes. Annu Rev Biochem. 1987;56:779827.

7. Bos JL. The ras gene family and human carcinogenesis. Mutat Res. 1988;195(3):255-271.

8. Malumbres M, Barbacid M. RAS oncogenes: the first 30 years. Nat Rev Cancer. 2003;3(6):459-465.

9. Junien C, McBride OW. Report of the committee on the genetic constitution of chromosome 11. Cytogenet Cell Genet. 1989;51(1-4):226-258.

10. Bos JL. ras oncogenes in human cancer: a review. Cancer Res. 1989;49(17):4682-4689.

11. Furth ME, Aldrich TH, Cordon-Cardo C. Expression of ras proto-oncogene proteins in normal human tissues. Oncogene. 1987;1(1):47-58.

12. Pethe V, Shekhar PV. Estrogen inducibility of c-Ha-ras transcription in breast cancer cells. Identification of functional estrogen-responsive transcriptional regulatory elements in exon 1/intron 1 of the c-Ha-ras gene. J Biol Chem. 1999;274(43):30969-30978.

13. Taparowsky E, Suard Y, Fasano O, Shimizu K, Goldfarb M, Wigler M. Activation of the T24 bladder carcinoma transforming gene is linked to a single amino acid change. Nature. 1982;300(5894):762-765.

14. Johne A, Roots I, Brockmoller J. A single nucleotide polymorphism in the human $\mathrm{H}$-ras proto-oncogene determines the risk of urinary bladder cancer. Cancer Epidemiol Biomarkers Prev. 2003;12(1):68-70.

15. Catela Ivkovic T, Loncar B, Spaventi R, Kapitanovic S. Association of H-ras polymorphisms and susceptibility to sporadic colon cancer. Int J Oncol. 2009;35(5):11691173.

16. Zhang Y, Jin M, Liu B, Ma X, Yao K, Li Q, Chen K. Association between H-RAS T81C genetic polymorphism and gastrointestinal cancer risk: a population based casecontrol study in China. BMC Cancer. 2008;8:256.

17. Rosaline H, Majdan R, Wan Z, et al. One-step multiplex RT-PCR for detection of BCR/ABL gene in Malay patients with chronic myeloid leukaemia. Asia Pacific Journal of Molecular Biology and Biotechnology. 2008;16(2):4144.

18. Zou X, Calame K. Signaling pathways activated by oncogenic forms of Abl tyrosine kinase. J Biol Chem. 1999;274(26):18141-18144.

19. Bos JL, Verlaan-de Vries M, van der Eb AJ, Janssen JW, Delwel R, Lowenberg B, Colly LP. Mutations in N-ras predominate in acute myeloid leukemia. Blood. 1987;69(4):1237-1241.

20. Bos JL, Toksoz D, Marshall CJ, Verlaan-de Vries M, 
Veeneman GH, van der $\mathrm{Eb} \mathrm{AJ}$, van Boom $\mathrm{JH}$, et al. Amino-acid substitutions at codon 13 of the N-ras oncogene in human acute myeloid leukaemia. Nature. 1985;315(6022):726-730.

21. Liu E, Hjelle B, Bishop JM. Transforming genes in chronic myelogenous leukemia. Proc Natl Acad Sci U S A. 1988;85(6):1952-1956.

22. Sathyan KM, Nalinakumari KR, Abraham T, Kannan S. Influence of single nucleotide polymorphisms in H-Ras and cyclin D1 genes on oral cancer susceptibility. Oral Oncol. 2006;42(6):607-613.

23. Kotsinas A, Gorgoulis VG, Zacharatos P, Mariatos G, Kokotas S, Liloglou T, Ikonomopoulos J, et al. Additional characterization of a hexanucleotide polymorphic site in the first intron of human H-ras gene: comparative study of its alterations in non-small cell lung carcinomas and sporadic invasive breast carcinomas. Cancer Genet Cytogenet. 2001;126(2):147-154.

24. Papadakis EN, Dokianakis DN, Spandidos DA. Genetic analysis of H-ras intron-1 polymorphic and variable tandem repeat regions in human breast cancer. Int $\mathrm{J}$ Biol Markers. 2003;18(3):195-199.

25. Castro P, Soares P, Gusmao L, Seruca R, Sobrinho-Si- moes M. H-RAS 81 polymorphism is significantly associated with aneuploidy in follicular tumors of the thyroid. Oncogene. 2006;25(33):4620-4627.

26. Kreimer-Erlacher H, Seidl H, Back B, Kerl H, Wolf P. High mutation frequency at Ha-ras exons 1-4 in squamous cell carcinomas from PUVA-treated psoriasis patients. Photochem Photobiol. 2001;74(2):323-330.

27. Yoo J, Park SY, Robinson RA, Kang SJ, Ahn WS, Kang CS. ras Gene mutations and expression of Ras signal transduction mediators in gastric adenocarcinomas. Arch Pathol Lab Med. 2002;126(9):1096-1100.

28. Murugan AK, Hong NT, Cuc TT, Hung NC, Munirajan AK, Ikeda MA, Tsuchida N. Detection of two novel mutations and relatively high incidence of H-RAS mutations in Vietnamese oral cancer. Oral Oncol. 2009;45(10):e161166.

29. Sathyan KM, Nalinakumari KR, Kannan S. H-Ras 81T -> C Polymorphism Associated with Oral Cancer Risk. Indian J Med Res. 2005;85 (2).

30. Magdalena T, Edyta B, Marek R, et al Polymorphic variants of H-RA S proto oncogene and their possible role in bladder cancer etiology. Central European Journal of Urology. 2012;65(2). 